\title{
HEMOGLOBIN STATUS OF FEMALE MEDICOS IN URBAN AREA AND FACTORS AFFECTING IT: AN OBSERVATIONAL CROSS-SECTIONAL STUDY
}

\author{
VARSHA KALYANPUR ${ }^{1}$, PADMAJA UDAYKUMAR ${ }^{2}$ \\ Father Muller Medical College, Mangalore, Karnataka, India. '2Department of Pharmacology, Father Muller Medical College, Kankanady, \\ Mangalore, Karnataka. Email: padmajaudaykumar@gmail.com
}

Received: 02 December 2016, Revised and Accepted: 21 December 2016

\section{ABSTRACT}

Objectives: Estimating the hemoglobin ( $\mathrm{Hb})$ status in female medicos through prospective cross-sectional study and assessment of influencing of cofactors were objectives.

Methods: Women medicos who volunteered, consented and met selection criteria were enrolled. Hb level was estimated to diagnose anemia. Relationship with influencing factors was assessed statistically.

Result: A total of 100 eligible students were enrolled. Mean age \pm standard deviation (SD) age of the participants' was 20.9 \pm 3.1 years (17-25 years). Mean \pm SD Hb was $12.25 \pm 1.0189 \mathrm{~g} \%$ (9.0-16.0 g\%). 33 were anemic, and mild anemia (32\%) was frequent. There was a history of worm infestation in three students (3\%), who were treated adequately. Nine were on iron supplements of which five were still anemic and were continuing the treatment by the end of the study. $28(84.84 \%)$ anemic students were not on any iron or hematinic treatment. There was no association between the anemia and nature of diet, consumption of green leafy vegetables, consumption of coffee/tea after food, smoking/tobacco or alcohol consumption, mother's education, socioeconomic status, menstrual factors, and physical exercise. The prevalence of anemia was found to be higher in underweight and overweight students in comparison to students with normal body mass index.Asymptomatic participants $(\mathrm{n}=78)$ outnumbered symptomatic ones $(\mathrm{n}=22)$, but without any statistical significance. Easy fatigability $(14 \%)$, pallor $(7 \%)$, breathlessness $(6 \%)$, weakness $(9 \%)$, and easy bruising $(1 \%)$ were frequent complaints.

Conclusion: Anemia is frequent among women medicos, often underdiagnosed, under-reported, many remaining asymptomatic. Negligence of medical students toward their anemic status despite the awareness of consequences of low $\mathrm{Hb}$ level is a serious cause of concern.

Keywords: Awareness, Hemoglobin, Nutritional anemia, Women medical students.

(c) 2017 The Authors. Published by Innovare Academic Sciences Pvt Ltd. This is an open access article under the CC BY license (http://creativecommons. org/licenses/by/4. 0/) DOI: http://dx.doi.org/10.22159/ajpcr.2017.v10i3.16440

\section{INTRODUCTION}

The nutritional disturbance is one of the common health problems next to infectious diseases among the adolescents and young adults due to the increased demands during the growth period. It is estimated that $25 \%$ of world's population are anemic with more disease burden reported from developing countries (43\%), particularly from Africa and Asia [1]. Developed countries are focused on another side of the coin, i.e., obesity and related comorbidities, while developing countries are still battling with malnourishment and infection having a huge impact on economic and social policies.

Available data indicate gender difference even globally with a high rate of anemia among young girls compared to boys. Female preponderance (73.5\% nonpregnant women) is seen worldwide. Among Asians too female preponderance is observed with $34 \%$ of nonpregnant females being anemic and worst ratio is seen in South East Asia where 85.4\% of nonpregnant females are anemic compared to men (4.1\%) [1]. It is estimated that $56 \%$ of young girls aged $15-24$ years are anemic India [2]. These statistics have made the governments to focus on improving the nutritional status. Younger children and school going children are covered under midday meal program, deworming, and iron supplements while adolescents and young adults are not covered under these programs which result in increased incidence of nutritional disturbance among this population. Due to socioeconomic and cultural reasons, in addition to poor diet and menorrhagia, girls and young women are affected the most [3]. Reports have revealed that even students among the educated, belonging to higher socioeconomic class have anemia (63-70.8\%) [4,5]. Medical fraternity including medical students is considered to be part of well-informed society and perceived by the general public as authority on health-related knowledge; surprisingly, most of our students have anemia as revealed by various studies. Saratha et al. reported that $76 \%$ of young adult female medical and nursing students were anemic [6].

Most of the data available included both male and female medicos, while there is no study done primarily on female medicos. Although study by Saratha et al. [6] was on female students they included even nursing students. Hence, we planned this study on our female medicos. We estimated the hemoglobin ( $\mathrm{Hb})$ status and assessed its correlates in young female medical students to highlight the under-recognized and under-reported condition.

\section{METHODS}

A cross-sectional observational study was conducted after obtaining approval from the ethical committee. A written informed consent was taken from the participants, emphasizing the voluntary nature of participation. Our primary objective was to assess the Hb status in female medical students. Assessment of the influence of cofactors, i.e., age, academic year, sociodemographic variation, and diet, relation between nutritional status body mass index (BMI) and $\mathrm{Hb}$ and establishing correlation of vitals (pulse, BP, and temperature) with $\mathrm{Hb}$ concentration were the secondary objectives. 
We included all healthy female medical students aged 17-25 years (both inclusive) who agreed to follow the study procedures and provided a written informed consent. We excluded those aged $<17$ and $>25$ years; diagnosed to have carcinoma, receiving frequent chemotherapy and radiotherapy, other systemic diseases which would affect the $\mathrm{Hb}$ status - bleeding tendency, thrombocytopenia, etc., those on antipsychotics, and recent blood transfusion in the last 3 months; married, pregnant, and lactating women were also excluded from the study.

Sociodemographic information of the participants was collected, which included: Age, physical exercise (nature and frequency of exercise), academic year and academic performance, rural or urban background, family income and socioeconomic status (classified using modified Kuppuswamy socioeconomic status) $[7,8]$ literary status of mother, number of family members, and detailed menstrual history. A selfreported diet history (Vegetarian or nonvegetarian, any change in the food habit - increase or decrease in intake, and source of food), use of concomitant medication and history of any disease or major surgery in the last 6 months were collected. The presence of any clinical signs and symptoms of nutritional deficiency or anemia was noted. History of worm infestations, regular deworming, and treatment received was collected.

Height, weight, pulse, blood pressure (BP), and temperature were recorded using standard methods and BMI was computed. Individuals were categorized as per the World Health Organization (WHO) guidelines [9].

For Hb estimation, venous blood was collected from all participants by qualified technicians after taking aseptic precautions. Cyanmeth-Hb method was used to estimate $\mathrm{Hb}$ and graded as per WHO standards [9]. $\mathrm{Hb}$ was analyzed at our hospital laboratory, accredited with National Accreditation Board for Testing and Calibrating Laboratories.

\section{Statistical analysis}

Data were collected using Microsoft Excel worksheet 2013. The collected data were analyzed by SPSS to find descriptive statistics - mean \pm standard deviation (SD), frequency, percentage, and inferential statistics analyzed using Chi-square test.

\section{RESULT}

A total of $100 \quad(n=100)$ eligible female medical students were enrolled. Mean \pm SD age of the participants' was $20.9 \pm 3.1$ with a range of 17-25 years. And a median age of 21 years. Mean \pm SD $\mathrm{Hb}$ was $12.25 \pm 1.0189$, with a range of $9.0-16.0 \mathrm{~g} \%$.

Of 100 participants, 33\% (n=33) were anemic and 67\% (n=67) were nonanemic. Among the anemic students had mild anemia (32\%) was frequent, $1 \%$ had moderate anemia. However, 53\% (n=53) had borderline values ranged from $12-13 \mathrm{mg} / \mathrm{dl}$.

Incidence of anemia was marginally higher in $>20$ years age group (35.59\%) as compared to $\leq 20$ years (29.3\%) (Table 1 ).

In comparison to first-year students (16.70\%), the $2^{\text {nd }}-4^{\text {th }}$-year students had a higher prevalence of anemia (Fig. 1) but were statistically insignificant $(\mathrm{p}=0.06)$.

No statistical significance was found between the occurrence of anemia and nature of diet. There was a narrow difference between prevalence of anemia among vegetarians $(38.9 \%)$ and nonvegetarians $(31.7 \%)$ $(\mathrm{p}=0.557)$ (Table 2).

\section{Literary status of mother}

There was a lower percentage of prevalence of anemia among students who's mother is graduate/post-graduate $(29 \%)$ compared to those whose mothers' education was less than graduation. However, no statistical significance could be established $(\mathrm{p}=0.45)$ (Table 3$)$.
Table 1: Age distribution among the study population

\begin{tabular}{llll}
\hline Age & Non-anemic & Anemic & Total \\
\hline 20 and below & 29 & 12 & 41 \\
Percentage of within age & 70.7 & 29.3 & 100 \\
Percentage of within Hb & 43.3 & 36.4 & \\
Above 20 & 38 & 21 & 59 \\
Percentage of within age & 64.41 & 35.59 & 100 \\
Percentage of within Hb & 56.7 & 63.6 & \\
Total & 67 & 33 & 100 \\
\hline
\end{tabular}

Hb: Hemoglobin

Table 2: Distribution of anemia among vegetarians and nonvegetarians

\begin{tabular}{llll}
\hline \multirow{2}{*}{ Diet } & \multicolumn{2}{l}{$\mathbf{n}(\mathbf{\%})$} & \\
\cline { 2 - 4 } & Non-anemic & Anemic & Total \\
\hline Vegetarian & $11(61.1)$ & $7(38.9)$ & $18(100.0)$ \\
Percentage of within $\mathrm{Hb}$ & 16.4 & 21.2 & 18.0 \\
Nonvegetarian & $56(68.3)$ & $26(31.7)$ & $82(100.0)$ \\
Percentage of within $\mathrm{Hb}$ & 83.6 & 78.8 & 82.0 \\
Total & 67 & 33 & 100 \\
\hline
\end{tabular}

Hb: Hemoglobin

Table 3: Literary status of mother and prevalence of anemia

\begin{tabular}{llll}
\hline $\begin{array}{l}\text { Literary status of } \\
\text { mother }\end{array}$ & $\mathbf{n}(\mathbf{\%})$ & \\
\cline { 2 - 4 } & Non-anemic & Anemic & Total \\
\hline$\leq 12^{\text {th }}$ standard & $14(56)$ & $11(44)$ & $25(100)$ \\
Graduate/post-graduate & $53(71)$ & $22(29)$ & $75(100)$ \\
Total & 67 & 33 & $100(100)$ \\
\hline
\end{tabular}

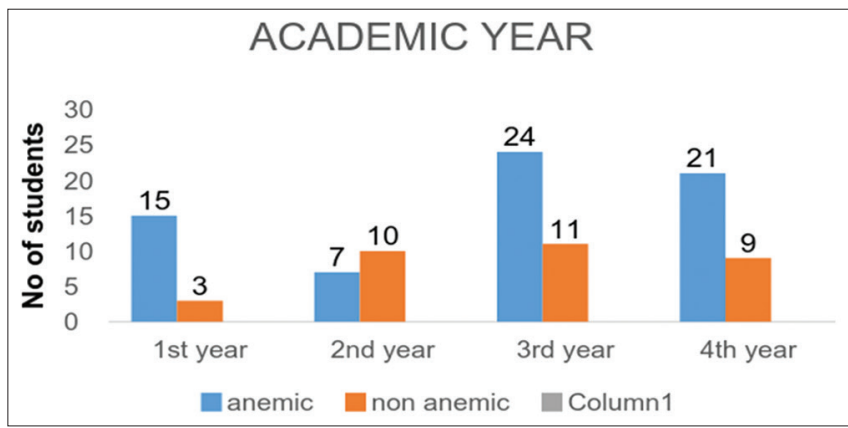

Fig. 1: Prevalence of anemia among the study population

There was no statistically significant relationship between anemic status of students and the socioeconomic status of family ( $p=0.169)$.

There was a history of worm infestation in three students (3\%), who were treated adequately. Nine students were on iron supplements of which five $(55.55 \%)$ were still anemic and were continuing the treatment by the end of the study. 28 (84.84\%) anemic students were not on any iron or hematinic treatment.

Association of anemia with age of menarche ( $\mathrm{p}=0.37)$, history of heavy bleed $(\mathrm{p}=0.982)$, duration of cycle $(\mathrm{p}=0.419)$, and irregular cycles $(\mathrm{p}=0.668)$ was statistically insignificant.

Similarly, physical exercises and anemia also did not show statistically significant relationship ( $\mathrm{p}=0.884)$.

The prevalence of anemia among young female medical students was not found to be significantly associated with tea/coffee $(p=0.62)$, smoking/tobacco $(p=0.39)$, or alcohol consumption $(p=0.98)$. The 
relation between consumption of green leafy vegetables and $\mathrm{Hb}$ levels were not found to be statistically significant $(p=0.37)$.

Asymptomatic participants $(n=78)$ outnumbered symptomatic ones $(n=22)$ with complaints of easy fatigability $(n=14,14 \%)$, pallor $(n=7$, $7 \%)$, breathlessness $(n=06,6 \%)$, weakness $(n=09,9 \%)$, and easy bruising $(n=01,1 \%)$. However, there was no statistical significance between symptomatic and asymptomatic patients $(\mathrm{p}=0.219)$ (Table 4).

The study showed no correlation between height, weight or BMI of students. BMI was within the normal range in $52(52 \%)$ participants while $24(24 \%)$ were underweight, $21 \%$ were overweight $(n=21)$, and $23 \%$ obese $(n=23)$ (Table 5$)$.

The prevalence of anemia was found to be higher in underweight and overweight students in comparison to students with normal BMI (Table 5).

Mean \pm SD height of the participants was $161 \pm 5.812 \mathrm{~cm}$, with a range of $149-178 \mathrm{~cm}$. Mean \pm SD weight of the participants was $54.52 \pm 8.785 \mathrm{~kg}$, with a range of 38-80 kg, and median weight of $53 \mathrm{~kg}$.

Mean BMI \pm SD BMI of the participants was $20.99 \pm 3.1$, with a range of 14.84-29.6 and median BMI of 18.69 .

Mean \pm SD temperature was $37.005^{\circ} \pm 0.005^{\circ}$, with a range of $36-38^{\circ} \mathrm{C}$. Association between temperature and $\mathrm{Hb}$ was statistically insignificant $(\mathrm{p}=0.031)$

Mean \pm SD pulse rate of the participants was $73.08 \pm 6.824$ beats/minute, with a range of 45-100 beats/minutes. Association between pulse rate and $\mathrm{Hb}$ was statistically significant $(\mathrm{p}=0.013)$.

Association between systolic $\mathrm{BP}$ and $\mathrm{Hb}$ was statistically significant $(\mathrm{p}=0.031)$, but there was no statistically significant association was found with diastolic BP $(\mathrm{p}=0.451)$ (Table 6).

\section{DISCUSSION}

Nutritional anemia is the most frequent cause of anemia worldwide. Despite increased awareness and availability of better nutrition, this clinical condition is still a major health issue in many developing countries including India. Its occurrence in women particularly in younger women not only affects her but also future generation. Thus, identifying and treating this common condition becomes important. The prevalence of anemia in South Asians is reported to be the highest in the world indicating the disease burden in this region, while in India, it is reported to be as high as $56 \%$ in young girls [2]. Bhanushali et al. reported that anemia is frequent among adolescent girls $26.87 \%$ were anemic [10]

Efforts from the medical fraternity along with government agencies have resulted in increased awareness about the disease and its common causes. Frequent medical examination, food fortification, and deworming have yielded improvement but not satisfactory as still a major percentage (79.2\%) of Indian population has anemia as indicated by a survey done in 2005-2006. Interestingly, girls were affected the most of $72.6 \%$ with nutritional anemia [11].

Physiological changes, peer pressure that influence the dietary habits have made young women more vulnerable to anemia. It is observed that the prevalence of anemia in young girls aged between 15 and 24 years is as high as $56 \%$ [2]. However, this report does not indicate the actual burden, as many remain asymptomatic, unnoticed and unreported.

It's a common belief that the magnitude of the problem is inversely proportional to the level of awareness. This has been proved even for anemia but in young adolescent girls [12], but not in young women. Chathuranga et al. reported $25 \%$ of women students were anemic among the university students [13]. We expect the medical students
Table 4: Symptoms reported by anemic population

\begin{tabular}{ll}
\hline Symptoms & n \\
\hline No symptoms & 78 \\
Breathlessness & 1 \\
Breathlessness, easy fatigability, weakness & 3 \\
Breathlessness, easy fatigability, weakness, pallor & 1 \\
Easy fatigability & 4 \\
Easy fatigability, pallor & 1 \\
Fatigability, breathlessness, weakness & 1 \\
Fatigability, weakness & 2 \\
Pallor & 5 \\
Weakness & 2 \\
Weakness, fatigability & 1 \\
Weakness, fatigability, bruising & 1 \\
Total & 100 \\
\hline
\end{tabular}

BMI: Body mass index

Table 5: BMI and anemic status of study population

\begin{tabular}{llll}
\hline BMI & \multicolumn{1}{l}{$\mathbf{n}(\mathbf{\%})$} & \\
\cline { 2 - 4 } & Anemic & Non-anemic & Total \\
\hline Underweight $<18.5$ & $11(45.83)$ & $13(54.16)$ & $24(24)$ \\
Normal 18.5-22.9 & $14(26.92)$ & $28(53.85)$ & $52(52)$ \\
Overweight 23-24.99 & $5(45.45)$ & $06(54.54)$ & $11(11)$ \\
Obese $>25$ & $3(23.07)$ & $10(76.92)$ & $13(13)$ \\
Total & $33(33)$ & $67(67)$ & $100(100)$ \\
\hline
\end{tabular}

BMI: Body mass index

Table 6: Relationship of BMI, vitals, and $\mathrm{Hb}$ among study population

\begin{tabular}{lll}
\hline Correlation of $\mathbf{H b}(\mathbf{g} / \mathbf{d} \mathbf{l})$ & $\begin{array}{l}\text { Pearson correlation } \\
\text { coefficient } \mathbf{r}\end{array}$ & $\mathbf{p}$ \\
\hline BMI & 0.066 & 0.516 \\
Temperature & 0.216 & $0.031^{*}$ \\
Pulse rate (bpm) & 0.248 & $0.013^{*}$ \\
SBP & 0.216 & $0.031^{*}$ \\
DBP & 0.076 & 0.451 \\
\hline
\end{tabular}

*Statistically significant, BMI: Body mass index, Hb: Hemoglobin

who study human health from the first year of their academic year to take care of their nutritional needs and health better than their counterparts. It is perplexing that the reports available state a high rate of anemia among this population (76\%) [6] which is unexpected that gave us the imitative to take up this study.

Available reports state the occurrence of anemia in India varies between $25 \%$ and $80 \%$ [14-24]. There is a higher prevalence (22-96.50\%) among adolescent girls $[18,23-25]$. Women medicos in this age group are no exception as $76 \%$ of Indian women medicos have overt nutritional anemia [6]. The low rate of anemia (8.0\%) has been reported from a hilly state of Northern India [26] while prevalence as high as $47.4 \%$ was seen in women medicos in central India, most of them were of mild in severity none had severe form [27]. In a study by Bano et al., which included all medical students, $44 \%(n=22)$ women medicos were anemic [28]. Among first and second year medicos, 38.46\% of women students were anemic [29]. Union Territory Pondicherry located in Southern India reported 76\% women medicos having anemia [6]. Our institution is located in the west coastal region of South India, and 33\% of our women medicos were anemic. This variation could be explained by demographic variations of the regions and the predominance of students from urban background (82\%) among the study population in our study.

Mild anemia is frequent among medicos, while no report of severe anemia in this population has been reported $[13,27,30]$. Bano et al. 
have reported mild anemia in 36\%, moderate anemia in $8.0 \%$ of women medicos [28], and there was no severe anemia among these students. Our result too is in agreement with this fact as only $32 \%$ had mild anemia. However, a concerning observation that $52 \%$ of our participants had $\mathrm{Hb}$ of $12-13 \mathrm{mg} / \mathrm{dl}$ indicating the vulnerability of students to anemia in the near future, if not intervened. None of our participants had severe anemia similar to the previous studies.

List of contributing factors for anemia is endless; hence, we focused only on few major factors. Age and academic year has been an influencing factor; Incidence of anemia increase with age and academic year of the students. This trend has been observed by other researchers too and higher rate of anemia [26]. This could be attributed to the increased academic stress, work schedule during the last years of education and extracurricular activities.

There is a negative association between BMI and anemia among women medicos [31], but the statistical significance was not established. We too observed negative association of BMI to $\mathrm{Hb}$ concentration among girls who were overweight and obese, but failed to demonstrate statistical significance. Similar result was observed among nonschool going [25] and school going [10] adolescent girls wherein BMI was statistically significant. Verma et al. have reported significant lower level of $\mathrm{Hb}$ among girls (82.4\%) having $\mathrm{BMI} \leq 18.5$ as compared to higher BMI $\left(>21.5 \mathrm{~kg}^{2}\right)$ in the slums of Ahmadabad city [32]. Negative association in this study could be related to the reduction in levels of estrogen binding protein levels with increasing adiposity (BMI) with concomitant increase in insulin. Therefore, levels of free estrogen may rise up which may cause suppression of erythropoiesis in females [33].

There are contradicting reports about the influence of socioeconomic status of the students on anemia. Bhanushali et al. reported a positive impact of socioeconomic status on the anemic status of young adolescent girls [10]. Socioeconomic status of our medical students did not have any significant association on anemia similar to the reports by Thomsen et al. [31] while Chaudhary and Dhage have shown a positive association with anemia [23].

Dietary habits of the individual determine the nutritional status. Our study revealed that there was no statistical significance between the occurrence of anemia in vegetarians $(38.9 \%)$ and nonvegetarians that were contradicting the observations of Saratha et al. [6] who reported less incidence of anemia in those who consumed nonvegetarian diet. consumption of tea immediately after food too did not have any significant effect. Bhanushali et al. reported that $26.92 \%$ of anemic students had a habit of post-meal consumption of coffee/tea [10]. Unlike Saratha et al. [6] who reported higher rate of anemia among those who consumed less of green leafy vegetables, our participants did not show any significant change. We attribute this to preliminary diet questionnaire or lack of efficient recall method.

The literacy rate of mother has shown definite impact on the prevalence of anemia in this population in terms of positive association $[10,23,31]$ and our study support this observation.

Menstruation does play an important role in the development of anemia; any irregularity associated with it, i.e., menorrhagia can deteriorate the condition. We could not demonstrate any significant relation between anemia and factors associated with menstruation, i.e., age of menarche, duration of cycle, history of heavy bleeding, and irregular cycle could not be established; in contrast, Saratha et al. [6] noted a positive association between anemia and menstrual factors.

Worm infestation is a well-established cause of nutritional anemia in our country, hence deworming is the first step in the management. We expected none of participants to have worm infestation; unexpected observation was that $3 \%$ of our participants had a history of worm infestation, and all had been treated adequately. Awareness of deworming among medical students could be one of the reasons for
$67 \%$ of the subjects to be non-anemic in our study. Saratha et al. [6] reported higher prevalence of worm infestation among their study population with a majority of them $(96.91 \%)$ reported to have anemia. An interesting observation by Bhanushali et al. was that $92.31 \%$ of their study population was free from intestinal parasites [10].

Many of our women medicos were asymptomatic (78\%). We observed a significant association between $\mathrm{Hb}$, body temperature $(\mathrm{p}=0.031)$, pulse rate $(0.013)$, and systolic BP (0.031). All these could be attributed to the hemodynamic changes caused by low Hb. Height did not have any influence on anemia in our medicos.

Anemia has significant effects on a student's health, endurance capacity, work productivity, and cognitive functioning and thereby affects academic performance. Therefore, there is a need of regular screening for anemia in female medical students.

Increasing reports of tiredness and lethargy among female adolescents and young adults requires immediate attention. Early detection and health intervention by necessary corrective measures will substantially prevent anemia. Hence, considerable effort is required to increase the awareness and provide better health facility to our future female doctors to tackle this simple, common and easy to treat condition.

Ours are the first study on women medicos while other studies have included male medicos, nursing students; hence, we did not have study to compare our results vis-a-vis. Our study highlights the underreported condition having long-term effect not only on the participants but also may have implications on future generation. Thus, it is imperative that appropriate diagnostic methods and early intervention to be considered in women medicos.

\section{CONCLUSION}

There is an increasing need of analysis of anemic status among the professional students including medical students as latter are not exempt from vulnerability. Asymptomatic nature disease may be a contributing factor for under diagnosis and under reporting. Negligence of medical students toward their anemic status despite the awareness of consequences of low $\mathrm{Hb}$ level is a serious cause of concern.

\section{ACKNOWLEDGMENT}

We thank the participants who willingly participated in the study, without their cooperation this study would not have been possible. We are thankful to the management of Father Muller Medical College for financial and technical support. We extend our thanks to Mrs. Sucharitha suresh for the statistical analysis and Dr. Latha for her valuable guidance and reviewing. We thank Anulekha writers for their writing support.

\section{REFERENCES}

1. Benoist B, McLean E, Egli I, Cogswell M, editors. Worldwide Prevalence of Anaemia 1993-2005: WHO Global Database on Anaemia. World Health Organization. (NLM Classification: WH 155). Available from: http://www.whqlibdoc.who.int/publications/2008/97892415966 57 eng.pdf. [Last accessed on 2016 Nov 19]

2. Parasuraman S, Kishor S, Vaidehi Y. National Family Health Survey (NFHS-3) India 2005-6, Gujarat. Ministry of Health \& Family Welfare of India: Gujarat National Family Health Survey India (2005-2006). International Institute for Population Sciences (IIPS) and Macro International; 2008. p. 122. Available from: http://www.rchiips.org/ nfhs/NFHS3\%20Data/gujarat_state_report_for_website.pdf. [Last accessed on 2016 Nov 19].

3. Kaur S, Deshmukh PR, Garg BS. Epidemiological correlates of nutritional anaemia in adolescent girls of rural Wardha. Indian $\mathrm{J}$ Community Med 2006;31:255-8.

4. Mehta K. Prevalence of nutritional anemia among college students and its correlation with their body mass index. Int J Sci Res 2015;4:1882-6.

5. Panat AV, Pathare SA, Asrar S, Rhokale GY. Iron deficiency among rural college girls: A result of poor nutrition and prolonged menstruation. J Community Nutr Health 2013;2:56-60. 
6. Saratha A, Singh Z, Datta S, Boratne AV, Senthilvel V. Prevalence of anaemia among young adult female students in a medical teaching institution in Pondicherry. Indian J Mater Child Health 2010;12(4):1-8.

7. Kuppuswamy B. Manual of Socioeconomic Status. New Delhi: Manasayan; 1981

8. Kumar BP, Dudala SR, Rao AR. Kuppuswamy's socio-economic status scale - A revision of economic parameter for 2012. Int J Res Dev Health 2013;1(1):2-4.

9. WHO. Haemoglobin Concentrations for the Diagnosis of Anaemia and Assessment of Severity. Vitamin and Mineral Nutrition Information System (WHO/NMH/NHD/MNM/11.1). Geneva: World Health Organization; 2011. Available from: http://www.who.int/vmnis/ indicators/haemoglobin.pdf. [Last accessed 2016 Nov 19].

10. Bhanushali MM, Shirode AR, Joshi YM, Kadam VJ. An intervention on iron deficiency anemia and change in dietary behavior among adolescent girls. Int J Pharm Pharm Sci 2011;3(1):402.

11. Singh LL, Bhat PN, Ram F, Paswan B. Nutritional status of children and prevalence of anemia among children, adolescent girls and pregnant women. District Level Household Survey on Reproduction and Child Health. India 2002-2004. International Institute for Population Sciences (Deemed University), Mumbai. New Delhi, India: India and Ministry of Health and Family Welfare Government of India. Available from: http://www.rchiips.org/pdf/rch2/national nutrition report rch-ii.pdf. [Last accessed on 2016 Nov 19].

12. Abedini S, Noraddin SH, Mohseni SH. The effect of education on knowledge of high school female's students of sirik about iron deficiency anemia. J Dev Strateg Med Educ 2015;2:20-5.

13. Chathuranga G, Balasuriya T, Perera R. Anaemia among female undergraduates residing in the hostels of university of Sri Jayewardenepura, Sri Lanka. Anemia 2014;2014:526308.

14. Vasanthi G, Pawashe AB, Susie H, Sujatha T, Raman L. Iron nutritional status of adolescent girls from rural area and urban slum. Indian Pediatr 1994;31(2):127-32.

15. Chaturvedi S, Kapil U, Gnanasekaran N, Sachdev HP, Pandey RM, Bhanti T. Nutrient intake amongst adolescent girls belonging to poor socioeconomic group of rural area of Rajasthan. Indian Pediatr 1996;33(3):197-201.

16. Teoteja GS, Singh P. Micronutrient Profile in Indian Population (Part-I). New Delhi: Indian Council Medical Research; 2002. p. 131-40.

17. Aggarwal KN. Assessment of Prevalence of Anaemia and Iron in Response to Daily/Weakly iron Folate Supplement in Adolescent Girls (10-18) from Urban Slums of North Delhi. UNICEF; 1998. p. 1-9.

18. Rajaratnam J, Abel R, Asokan JS, Jonathan P. Prevalence of anaemia among girls of Tamil Nadu. Indian Pediatr 2000;37(5):532-6.

19. Seshadri SA. Database on iron deficiency anaemia (IDA) in India:
Prevalence, causes, consequences and strategies for prevention. WHO Collaborating Centre for Nutrition Research. Vadodara, India: Department of Foods and Nutrition, The Maharaja Sayajirao University of Baroda; 1999.

20. Sivakumar B, Brahmam GN, Madhavan Nair K, Ranganathan S, Vishnuvardhan Rao M, Vijayaraghavan K, et al. Prospects of fortification of salt with iron and iodine. Br J Nutr 2001;85 Suppl 2:S167-73.

21. Gawarikar RS, Gawarikar SB, Tripathi BC. Prevalence of anaemia in adolescent girls of Ujjain in Western M.P. Indian J Nutr Diet 2002;39:493-9.

22. Sidhu S, Kumari K, Uppal M. Prevalence of anaemia among adolescent girls of scheduled caste community of Punjab. Anthropol J 2005; 7:265-7

23. Chaudhary SM, Dhage VR. A study of anemia among adolescent females in the Urban area of Nagpur. Indian J Community Med 2008;33:243-5.

24. Toteja GS, Singh P, Dhillon BS, Saxena BN, Ahmed FU, Singh RP, et al. Prevalence of anemia among pregnant women and adolescent girls in 16 districts of India. Food Nutr Bull 2006;27(4):311-5.

25. Bulliyy G, Mallick G, Sethy GS, Kar SK. Hemoglobin status of nonschool going adolescent girls in three districts of Orissa, India. Int $\mathrm{J}$ Adolesc Med Health 2007;19(4):395-406.

26. Saxena Y, Shrivastava A, Saxena V. Effect of gender on correlation of anaemia with body mass index in medical students. Indian J Physiol Pharmacol 2011;55(4):364-9.

27. Pandey S, Singh A. A cross sectional study of nutritional anaemia among medical students in a medical college at Bilaspur, Chhatisgarh. Natl J Med Res 2013;3(2):143-6.

28. Bano R, Ahmed N, Sharma BC, Agarwal A. Nutritional anemia in the medical students. Indian Med Gaz 2012;145(1):16-8.

29. Bano R, Waseem SM, Ahmad N. Study of haemoglobin status in first and second year MBBS students. Res Rev J Med 2015;5:16-8.

30. Khan B, Sukshohale ND, Jawade P. Prevalence of anemia among undergraduate medical students of Central India. GJRA Glob J Res Anal 2015;4(5):13-4

31. Thomsen K, Riis B, Krebbe S, Christiansen C. Testosterone regulates the hemoglobin concentration in male puberty. Acta Paediatr Scand 1986;75(5):793-6

32. Verma A, Rawal VS, Kedia G, Kumar D, Chauhan J. Factors influencing anemia among girls of school going age (6-18 years) from the slums of Ahmadabad city. Indian J Community Med 2004;29(1):25-6.

33. Lukanova A, Lundin E, Zeleniuch-Jacquotte A. Body mass index, circulating levels of sex-steroid hormones, IGF-I and IGF-binding protein-3: A cross-sectional study in healthy women. Eur J Endocrinol 2004;150(2):161-71. 